
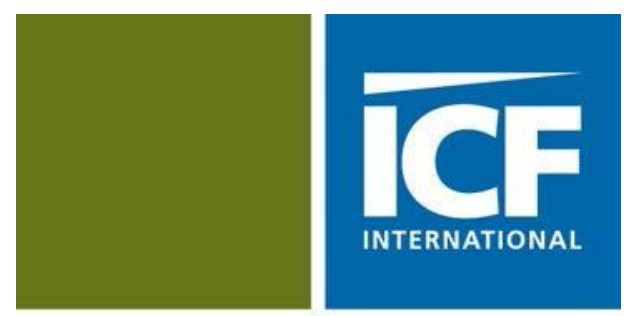

Using Cost-Effectiveness Tests to Design CHP Incentive Programs

November 2014

Prepared for:

Oak Ridge National Laboratory

Prepared by:

Joel Bluestein

Rick Tidball

ICF International
Priya Sreedharan Snuller Price Energy and Environmental Economics (E3) 


\section{DOCUMENT AVAILABILITY}

Reports produced after January 1, 1996, are generally available free via the U.S. Department of Energy (DOE) Information Bridge.

Web site http://www.osti.gov/bridge

Reports produced before January 1, 1996, may be purchased by members of the public from the following source.

National Technical Information Service

5285 Port Royal Road

Springfield, VA 22161

Telephone 703-605-6000 (1-800-553-6847)

TDD 703-487-4639

Fax 703-605-6900

E-mail info@ntis.gov

Web site http://www.ntis.gov/support/ordernowabout.htm

Reports are available to DOE employees, DOE contractors, Energy Technology Data Exchange (ETDE)

representatives, and International Nuclear Information System (INIS) representatives from the following source.

Office of Scientific and Technical Information

P.O. Box 62

Oak Ridge, TN 37831

Telephone 865-576-8401

Fax 865-576-5728

E-mail reports@osti.gov

Web site http://www.osti.gov/contact.html

This report was prepared as an account of work sponsored by an agency of the United States Government. Neither the United States Government nor any agency thereof, nor any of their employees, makes any warranty, express or implied, or assumes any legal liability or responsibility for the accuracy, completeness, or usefulness of any information, apparatus, product, or process disclosed, or represents that its use would not infringe privately owned rights. Reference herein to any specific commercial product, process, or service by trade name, trademark, manufacturer, or otherwise, does not necessarily constitute or imply its endorsement, recommendation, or favoring by the United States Government or any agency thereof. The views and opinions of authors expressed herein do not necessarily state or reflect those of the United States Government or any agency thereof. 
Energy and Transportation Science Division

\title{
Using Cost-Effectiveness Tests to Design CHP Incentive Programs
}

\author{
Prepared by \\ ICF International \\ 9300 Lee Highway \\ Fairfax, Virginia 22031 \\ and \\ Energy and Environmental Economics (E3) \\ 101 Montgomery Street \\ San Francisco, California 94104 \\ under Subcontract 40000107316 \\ Date Published: November 2014 \\ Prepared for \\ OAK RIDGE NATIONAL LABORATORY \\ Oak Ridge, Tennessee 37831-6283 \\ managed by \\ UT-BATTELLE, LLC \\ for the \\ U.S. DEPARTMENT OF ENERGY \\ under contract DE-AC05-00OR22725
}




\section{Table of Contents}

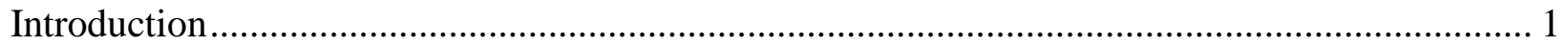

Benefits of Combined Heat and Power.............................................................................. 2

Background on Distributed Energy Resources and Cost-Effectiveness Tests............................ 3

Applying Cost-Effectiveness Frameworks to Combined Heat and Power ................................. 8

Illustrative Examples Based on CHP Analysis in Five States ............................................. 10

Cost-Effectiveness Test Recommendations for States Establishing CHP Programs.................. 16

\section{List of Figures}

Figure 1. Efficiency Benefits of CHP .......................................................................... 2

Figure 2. Total resource cost test results for all five states ................................................. 10

Figure 3. Energy avoided costs used for 5 states ....................................................... 11

Figure 4. Total resource cost test, Iowa, 40 MW CHP system .............................................. 12

Figure 5. Societal cost test, Iowa, 40 MW CHP system ...................................................... 12

Figure 6. Participant cost test with sensitivity on standby rates and demand charges................ 13

Figure 7. Societal cost test benefit to cost ratio vs. avoided costs for all CHP technologies ....... 14

\section{List of Tables}

Table 1. Five principal cost-effectiveness tests .............................................................. 4

Table 2. Summary of benefits and costs included in the cost-effectiveness tests........................ 4

Table 3. Program benefits and costs for electricity and natural gas use ................................... 6

Table 4. Comparison of PURPA and DER avoided costs ................................................. 7 


\section{Introduction}

Combined heat and power (CHP) is an efficient, clean and resource-prudent approach for meeting both electricity and thermal needs. A CHP system provides both electricity and thermal energy - typically in the form of hot water or steam - from a single energy-efficient technology. CHP reduces the need for grid electricity and offsets the need for boiler fuel that would otherwise be required to produce steam or hot water.

While some applications of CHP are relatively mature, others are still emerging and market forces alone may not drive their adoption. Ratepayer-funded programs ${ }^{1}$ can support CHP deployment and are currently used in several states, including California, Connecticut, Maryland and New York. ${ }^{2}$ Ratepayer-funded programs are widely used in many states to implement energy efficiency, demand response, and other distributed energy resource (DER) programs, but are less common for CHP programs.

Cost-effectiveness is often used by utility regulatory commissions to determine whether ratepayer funds should be used to support energy efficiency programs. Standard costeffectiveness tests have been developed to assist regulatory commissions in assessing the benefits of distributed resource programs and these tests are used to evaluate CHP incentive programs as well. CHP has unique characteristics that need to be appropriately accounted for in the DER cost-effectiveness framework. In particular, CHP generally increases on-site fuel use (typically natural gas) and produces both electric and thermal energy that must be accounted for properly.

This paper examines the structure of cost-effectiveness tests to illustrate how they can accurately reflect the costs and benefits of CHP systems. The underlying premise is that CHP systems are treated as a demand side or energy efficiency resource, rather than as a supply side generation resource, which is the traditional way in which CHP systems are viewed by regulatory commissions. This paper begins with a general background discussion on cost-effectiveness analysis of DER and then describes how cost-effectiveness tests can be applied to CHP. Costeffectiveness results are then calculated and analyzed for CHP projects in five states: Arkansas, Colorado, Iowa, Maryland, and North Carolina. Based on the results obtained for these five states, this paper offers four considerations to inform regulators in the application of costeffectiveness tests in developing CHP programs.

- Identify goals of the CHP program.

- Establish cost-effectiveness analysis steps, paying particular attention to avoided costs.

- Design performance based incentives that reward electrical and thermal performance.

- Provide visibility into the CHP system performance to promote confidence in utility distribution engineers. 


\section{Benefits of Combined Heat and Power}

A well designed CHP system can be expected to operate at 65-80 percent overall efficiency. In contrast, when grid electricity and boiler fuel are supplied separately, the overall efficiency is in the range of 45-50 percent (comparison shown in Figure 1).

\section{Figure 1. Efficiency Benefits of CHP3}

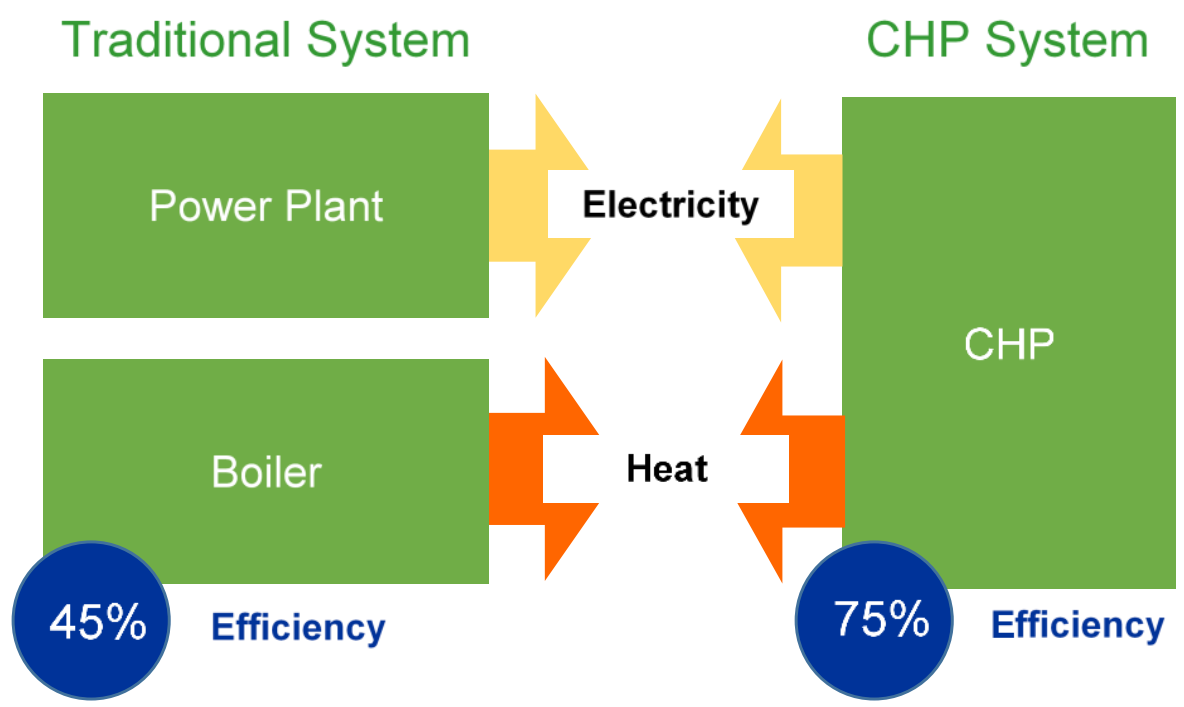

Source: DOE and EPA, $2012^{4}$

Compared to traditional thermal and power production systems (i.e., separate heat and power), CHP provides several benefits. These benefits include reduced overall fuel consumption, lower emissions of criteria pollutants, and reduced greenhouse gas emissions (GHGs). For perspective, the $\mathrm{CO}_{2}$ emissions from a $5 \mathrm{MW}$ natural gas-fired $\mathrm{CHP}$ system are approximately half the $\mathrm{CO}_{2}$ emissions compared to separate heat and power with the same energy output. ${ }^{5}$

Recognizing the benefits of CHP, the White House in 2012 issued Executive Order 13624 to "coordinate and strongly encourage efforts to achieve a national goal of deploying 40 gigawatts of new, cost-effective industrial CHP in the United States by the end of 2020." Achieving this goal may result in a number of benefits, including: ${ }^{7}$

- Energy cost savings of $\$ 10$ billion a year compared to current energy use

- Annual energy savings of one quadrillion Btus - equivalent to 1 percent of all energy use in the U.S.

- Reductions of 150 million metric tons per year of $\mathrm{CO}_{2}$ - equivalent to removing 25 million cars

- $\$ 40-80$ billion in new capital investment over the next decade 


\section{Background on Distributed Energy Resources and Cost- Effectiveness Tests}

Cost-effectiveness has a specific meaning in the state utility regulatory commission (often called Public Utility Commission, or PUC) context. The basic principles of DER cost-effectiveness are described here, drawing heavily from the National Action Plan for Energy Efficiency's

"Understanding Cost-Effectiveness of Energy Efficiency Programs" 8 and the California Standard Practice Manual. ${ }^{9}$

The development of cost-effectiveness methods dates back to the 1970s with the establishment of early energy efficiency programs. Cost-effectiveness is evaluated from multiple perspectives. The framework has evolved to evaluate other DER programs, such as demand response and distributed generation, and the quality of data and inputs have changed; however, the fundamental framework has not changed significantly since its inception.

\section{Structure of cost-effectiveness tests}

Cost-effectiveness calculations are based on a lifecycle approach that compares lifetime benefits and costs. Cost-effectiveness results can be expressed in terms of dollars or as a benefit to cost ratio as shown in the following equations:

$$
\begin{aligned}
& \text { Net Benefits (dollars) }=N P V \sum_{k=1}^{n} \text { benefits (dollars) }-N P V \sum_{k=1}^{n} \text { costs (dollars) } \\
& \text { Benefit to Cost ratio }=\frac{N P V \sum_{k=1}^{n} \text { benefits (dollars) }}{N P V \sum_{k=1}^{n} \text { costs (dollars) }}
\end{aligned}
$$

where " $k$ " represents a specific year over the measure lifetime of " $n$ " years. A benefit to cost ratio that exceeds one indicates that the net present value (NPV) of the benefits exceeds the NPV of the costs.

\section{Five cost-effectiveness tests}

There are five principal cost-effectiveness tests (see Table 1). Each addresses cost-effectiveness from a different perspective and comprises a specific set of costs and benefits. 
Table 1. Five principal cost-effectiveness tests

\begin{tabular}{|l|l|l|l|}
\hline Test & Acronym & Key question answered & Summary of approach \\
\hline $\begin{array}{l}\text { Participant } \\
\text { Cost Test }\end{array}$ & PCT & $\begin{array}{l}\text { Will participants benefit } \\
\text { over the measure life? }\end{array}$ & $\begin{array}{l}\text { Comparison of costs and benefits of } \\
\text { the customer installing the measure }\end{array}$ \\
\hline $\begin{array}{l}\text { Program } \\
\text { Administrator } \\
\text { Cost Test }\end{array}$ & PACT & Will utility bills increase? & $\begin{array}{l}\text { Comparison of program administrator } \\
\text { costs to supply-side resource costs }\end{array}$ \\
\hline $\begin{array}{l}\text { Ratepayer } \\
\text { Impact } \\
\text { Measure }\end{array}$ & RIM & Will utility rates increase? & $\begin{array}{l}\text { Comparison of administrator costs and } \\
\text { utility bill reductions to utility resource } \\
\text { costs }\end{array}$ \\
\hline $\begin{array}{l}\text { Total } \\
\text { Resource } \\
\text { Cost Test }\end{array}$ & TRC & $\begin{array}{l}\text { Will total energy costs in } \\
\text { the utility service territory } \\
\text { decrease? }\end{array}$ & $\begin{array}{l}\text { Comparison of program administrator } \\
\text { and customer costs to utility resource } \\
\text { savings }\end{array}$ \\
\hline $\begin{array}{l}\text { Societal Cost } \\
\text { Test }\end{array}$ & SCT & $\begin{array}{l}\text { Is the utility, state, or } \\
\text { nation better off as a } \\
\text { whole? }\end{array}$ & $\begin{array}{l}\text { Comparison of society's costs of } \\
\text { energy efficiency to resource savings } \\
\text { and non-monetary costs and benefits }\end{array}$ \\
\hline
\end{tabular}

Source: National Action Plan for Energy Efficiency, adapted from the Standard Practice Manual: Economic Analysis of Demand-side Programs and Projects. ${ }^{10}$

\section{Components of cost-effectiveness tests}

Each cost-effectiveness test requires specific inputs as shown in Table 2. A benefit in one test may represent a cost to another. Utility incentives, for example, are a benefit to the participant of the program but a cost to the utility.

Table 2. Summary of benefits and costs included in the cost-effectiveness tests

\begin{tabular}{|l|l|l|l|l|l|}
\hline Cost/benefit parameter & PCT & PACT & RIM & TRC & SCT \\
\hline Energy and capacity avoided costs & --- & Benefit & Benefit & Benefit & Benefit \\
\hline $\begin{array}{l}\text { Additional resource savings, such as } \\
\text { natural gas }\end{array}$ & --- & --- & --- & Benefit & Benefit \\
\hline Societal non-monetized benefits & --- & --- & --- & --- & Benefit \\
\hline $\begin{array}{l}\text { Incremental equipment and installation } \\
\text { costs }\end{array}$ & Cost & --- & --- & Cost & Cost \\
\hline Program overhead costs & --- & Cost & Cost & Cost & Cost \\
\hline $\begin{array}{l}\text { Utility incentives, payments, subsidies, and } \\
\text { tax credits }\end{array}$ & Benefit & Cost & Cost & --- & --- \\
\hline $\begin{array}{l}\text { Federal incentives, payments, subsidies, } \\
\text { and tax credits }\end{array}$ & Benefit & --- & --- & Benefit & Benefit \\
\hline Bill savings & Benefit & --- & Cost & --- & --- \\
\hline
\end{tabular}

Source: Standard Practice Manual: Economic Analysis of Demand-side Programs and Projects. ${ }^{11}$

Note: Incentive payments include any equipment and installation costs paid by the program administrator. 
Each parameter is described below. For additional details, the reader is referred to the National Action Plan Cost-Effectiveness Guide. ${ }^{12}$

- Energy and capacity avoided costs: These costs represent the avoided energy and avoided capacity costs to the utility. Energy-based avoided costs refer to market prices of energy, fuel costs, natural gas commodity prices, and other variable costs. Capacity-based avoided costs refer to infrastructure investments such as power plants, transmission and distribution lines, and pipelines.

- Additional resource savings: Resource savings not realized by the utility (i.e. customer gas or fuel oil savings in the case of an electric-only utility) are considered towards evaluation of the overall benefits to the region.

- Non-monetized benefits: Non-monetized benefits represent externalities such as health impacts due to reduced air pollutant emissions and water savings. These distinguish the TRC from the SCT. In some states, this is treated as a simple adder.

- Incremental equipment and installation costs: The incremental cost represents the cost of the measure installed as part of the program, net of the cost of the measure that would have been installed by the participant in the absence of a program.

- Program administrative costs: The cost to administer a program is factored into all cost tests except for the participant cost test. Note that program administrative costs are separate from the incentive payments.

- Incentive payments: There may be utility, state or federal incentive payments. Utility and state incentives are typically considered transfers between participants and nonparticipants in the cost-effectiveness test and are not included in the TRC or SCT. Federal incentives are typically considered benefits to the state or utility service territory and are benefits in the TRC and SCT as well as the PCT.

- Bill savings: The inclusion of bill savings is more complex when multiple fuel types are saved. The participant cost test requires the consideration of all fuel type savings (or in the case of CHP, the additional cost for natural gas, or additional bill costs from standby rates). From the utility perspective (RIM test), only the bill savings corresponding to the energy delivered by the respective utility is considered. In most cases, the RIM test is only calculated to evaluate the effect on non-participating electric customers and therefore only considers the electric bill savings.

Utility avoided costs are the primary benefits for all tests, with the exception of the participant cost test. Energy-related avoided costs include the market price of electricity that utilities would otherwise pay, or fuel and variable maintenance cost saving for vertically integrated utilities, loss savings, and natural gas commodity prices to the utility. Environmental benefits associated with energy production such as reduced air emissions and water usage may be considered, although, strictly speaking, only monetized environmental benefits are included in the TRC test (such as greenhouse gas or other allowance prices in cap and trade markets). Capacity-related avoided 
costs involve infrastructure investments such as power plants, transmission and distribution lines, and pipelines.

Table $3^{13}$ describes the components of possible benefits and costs to be considered for programs that affect electricity and natural gas use. The scope of appropriate avoided cost components is typically determined by the state utility regulatory commission. In order to appropriately capture the costs and benefits of CHP, both the electricity and natural gas effects must be considered. A typical CHP installation will increase the use of on-site fuel (typically natural gas), but this natural gas produces both thermal energy (offsetting boiler fuel use) and electricity (offsetting utility electric generation). If the CHP system is operating well, the higher system efficiency will lead to lower fuel use overall. Table 3 shows the energy and capacity related benefits of reducing electricity and natural gas use, or the increased costs of increased use.

Table 3. Program benefits and costs for electricity and natural gas use

\begin{tabular}{|l|l|}
\hline Electricity Benefits and Costs \\
\hline Energy & Capacity \\
\hline $\begin{array}{l}\text { Market purchases of fuel; operation and } \\
\text { maintenance costs }\end{array}$ & $\begin{array}{l}\text { Capacity purchases or generator } \\
\text { construction and maintenance costs }\end{array}$ \\
\hline System losses & System losses (peak load) \\
\hline Ancillary services related to energy & Transmission facilities \\
\hline Energy market price reductions & Distribution facilities \\
\hline Co-benefits in water, natural gas, fuel oil, etc. & Ancillary services related to capacity \\
\hline Air emissions & Capacity market price reductions \\
\hline Hedging costs & Land use \\
\hline Natural Gas Benefits and Costs & \\
\hline Energy & Capacity \\
\hline Market commodity purchases at city gate & Firm supply contracts \\
\hline Losses & Pipeline contracts \\
\hline Air emissions & Cold weather action/pressurization activities \\
\hline Market price reductions & Storage facilities \\
\hline Co-benefits in water, natural gas, fuel oil, etc. & LNG terminal contracts \\
\hline Hedging costs & Distribution facilities \\
\hline
\end{tabular}

Source: National Action Plan on Energy Efficiency, Understanding Cost-Effectiveness of Energy Efficiency Programs.

The avoided costs used in the state utility regulatory context for DER cost-effectiveness are similar in concept, but not the same as the avoided costs that fall under the Public Utilities Regulatory Policies Act of 1978 (PURPA). PURPA requires utilities to purchase power from qualifying CHP facilities at the utility's incremental energy and capacity costs that they would have incurred without CHP. ${ }^{14}$ These payments are also referred to as 'avoided costs,' but are used for different purposes, derived using different methodologies, and regulated by different entities (FERC vs. State Commission). Table 4 contrasts these categories of avoided costs. 
Table 4. Comparison of PURPA and DER avoided costs

\begin{tabular}{|l|l|l|}
\hline Test & \multicolumn{1}{|c|}{ DER avoided costs } & \multicolumn{1}{|c|}{ PURPA avoided costs } \\
\hline $\begin{array}{l}\text { Short run vs. } \\
\text { long run } \\
\text { avoided costs }\end{array}$ & $\begin{array}{l}\text { Can be based on a mix of short-run \& long-run } \\
\text { marginal costs to most accurately reflect } \\
\text { benefits to ratepayers }\end{array}$ & $\begin{array}{l}\text { Set at long run marginal } \\
\text { cost }\end{array}$ \\
\hline Jurisdiction & State regulatory utility commission jurisdiction & FERC jurisdiction \\
\hline Purpose & $\begin{array}{l}\text { Used for program design screening and are } \\
\text { not used for payments to customers }\end{array}$ & $\begin{array}{l}\text { Used to determine } \\
\text { payment to qualified } \\
\text { facilities }\end{array}$ \\
\hline Scope & $\begin{array}{l}\text { Both energy produced and consumed onsite } \\
\text { and energy produced and exported }\end{array}$ & $\begin{array}{l}\text { Only energy exported to } \\
\text { the utility }\end{array}$ \\
\hline
\end{tabular}

\section{Choosing cost-effectiveness tests for utility program design}

The TRC and SCT cost tests are generally used by utility commissions as primary tests to determine whether a DER program is cost-effective overall. ${ }^{15}$ The distinction is that the SCT test includes non-monetized benefits and therefore provides a broader view of societal costeffectiveness. Some states utilize the SCT in place of the TRC, and in other cases, a 'modified' TRC is used, which reflects a hybrid between the SCT and TRC. For the same reason that TRC and SCT are appropriate cost tests for DER, they are appropriate for CHP as well. Encouraging efficient CHP that is cost-effective from the TRC and SCT perspectives will provide long-term cost savings as do other efficiency programs. Less frequently, the PACT or RIM tests are used as the primary tests but treating these tests as primary tests will have relatively specific outcomes. The RIM test, used in one or two states, will limit investment in energy efficiency or any program that reduces load by including reduced customer bills as a cost. The PACT test will have the reverse effect and support increased DER investment by excluding the costs of the host customer's investment.

It is common practice for regulatory commissions to require the evaluation of more than one cost test. The three tests in addition to TRC and SCT are the PCT, PACT, and RIM, which are distributional tests that identify the 'winners' and 'losers' when a program is deployed. While the TRC and SCT assess the value of the DER resource on an overall societal basis, the distributional cost tests assess the economic impacts from different stakeholder perspectives within the utility service territory - the PCT from the participant view, the PACT from the perspective of the utility, government agency or third party implementing the program, and the RIM from the view of non-participant ratepayers. In 2012, 44 state regulatory commissions required the calculation of at least one distributional test as a secondary test.

Regulators can use a combination of the cost tests to design programs that make optimal use of ratepayer funds and support CHP deployment. If broad cost-effectiveness is the goal, the TRC or SCT can be used to determine if a program is appropriate overall. Next, incentive levels can be determined by using the distribution tests (RIM, PACT, and PCT) as guidelines to balance incentive levels, goals for adoption rates, and costs to ratepayers. 


\section{Applying Cost-Effectiveness Frameworks to Combined Heat and Power}

As with all DER, cost-effectiveness tests can help inform regulators on how to make the best use of ratepayer funds to encourage beneficial customer investments. A $\mathrm{kWh}$ of electricity saved or a $\mathrm{kW}$ of demand reduction has the same value to the grid whether that reduction was delivered by energy efficiency, demand response, permanent load shifting, combined heat and power or some other distributed generation resource. Therefore, CHP projects that pass the TRC or SCT should be encouraged to reduce overall costs.

The benefits of CHP are analogous to the benefits of conventional energy efficiency measures that save energy. To achieve the correct results, the framework must include the value of electricity savings, and the net change in fuel use considering fuel offset by thermal energy. The latter assessment must consider how the thermal energy would otherwise have been delivered, typically a boiler. Within the overall framework, it is also important to appropriately value additional resource savings, capacity value, and non-energy benefits. Each of which is discussed in more detail.

\section{Additional resource savings}

CHP avoids natural gas (or other on-site fuel) that would otherwise be used to produce thermal energy (e.g., in an on-site boiler), but requires natural gas (or other fuel) as a fuel input to the CHP system, which produces both thermal energy and electricity. The cost-effectiveness calculation must properly account for the net impact on natural gas consumption, which may result in an increase in site level natural gas consumption. Consider a simple example of a 1 MW CHP unit that has the following characteristics: heat rate of 10,000 Btu/kWh; 4,000 Btu/kWh thermal output; 75 percent avoided boiler efficiency. For one hour of full load operation, the CHP system consumes 10 MMBtu, but avoids 5.3 MMBtu of natural gas consumption by the boiler, resulting in a net site level natural gas consumption of 4.7 MMBtu. Assuming 8 percent for electric grid transmission and distribution losses, $1 \mathrm{MWh}$ of generation from the CHP system offsets approximately 1.1 MWh of grid electricity.

The cost-effectiveness framework directly lends itself to evaluating the benefits and costs of CHP. Table 2, which lists the cost and benefit components, is applicable for CHP. For electric only utilities, the natural gas savings (or increases in the case of CHP) must be reflected in the TRC and SCT tests, but not in the RIM and PAC test. This treatment occurs because natural gas is a resource that falls outside of the electric utility jurisdiction. Natural gas bill savings are reflected in the PCT, since these savings directly impact the participant. 


\section{Capacity value of CHP}

From a grid perspective, energy efficiency and CHP both provide the benefit of reducing systemlevel electricity consumption. One issue to be resolved for CHP, however, is the reliability of delivering the desired load impact and the resulting capacity value of CHP. From a grid perspective, it is important to consider CHP reliability at the program level and not at the level of a single CHP unit. It is possible that an individual CHP unit could go off-line at a time of high demand. A CHP program, however, would likely include many individual CHP units, and the impact of an unplanned outage from a single unit would be relatively small at the program level. Resource diversity significantly increases the likelihood that a CHP program will deliver generation capacity value (typically referred to as "system capacity") when required. For similar reasons, CHP can provide high voltage transmission system capacity benefits as well as generation system capacity benefits. As an example, the California Public Utilities Commission considers resource adequacy costs as a benefit in the distributed generation cost benefit methodology. ${ }^{16}$

The treatment of capacity value at the sub-transmission and distribution (T\&D) level has been a source of debate because utility distribution engineers have been hesitant to rely on CHP for capacity and there are fewer systems and less diversity of systems to rely upon. Standard practice for distribution planning is to use heuristic criteria to plan capacity investments, rather than probabilistic assessments of the likelihood of an outage, and CHP is difficult to account for in the heuristics. In practice, from our investigation of CHP cost-effectiveness in five states, the portion of the total value of distribution capacity is small (less than $\$ 0.008 / \mathrm{kWh}$ ) relative to the total benefits of CHP and including or excluding consideration of distribution does not change the cost-effectiveness result significantly.

\section{Non-energy benefits and costs}

Like energy efficiency, CHP can provide environmental benefits in the form of avoided criteria air pollutant emissions (and resulting health impacts); reduced GHG emissions; reduced water consumption required at central power stations; reduced land use for central power generation plants, and reduced transmission and distribution infrastructure. The cost-effectiveness framework traditionally incorporates non-monetized benefits in the SCT. However, in jurisdictions with environmental markets, such as California, and the Northeast (Regional Greenhouse Gas Initiative), GHG emissions are a monetized avoided cost and can be incorporated into the utility avoided cost. $\mathrm{SO}_{2}$ and $\mathrm{NO}_{\mathrm{x}}$ emissions can also be monetized where similar programs apply.

\section{State level activity}

Although the development of ratepayer funded energy efficiency programs has a multi-decade history, the application of cost-effectiveness tests to establish ratepayer-funded CHP programs is far less common. Virtually every state has some type of energy efficiency program, while CHP 
programs currently exist in only a few states (e.g., California, Connecticut, Maryland and New York). ${ }^{17}$

\section{Illustrative Examples Based on CHP Analysis in Five States}

The primary cost test used in most states is the TRC test. ${ }^{18}$ DER that is cost-effective from this perspective will provide long term cost savings because of the higher efficiency of CHP systems.

Figure 2 provides a summary of the base case TRC results in each of the five states using the avoided costs reported for those states (with the exception of Arkansas, where market data was used). The cost-effectiveness was analyzed for five different CHP applications that spanned small and large CHP applications and customer types, ranging from approximately $300 \mathrm{~kW}$ to 40 MW. In addition to the traditional topping cycle CHP applications, we also analyzed one bottoming cycle application (also known as waste heat to power [WHP]) and one CHP system with thermal energy recovered for space cooling (for a data center). To develop this assessment, we reviewed current practices in each state regarding DER cost-effectiveness evaluation, interviewed key stakeholders, and collected publicly available avoided cost data.

Figure 2. Total resource cost test results for all five states

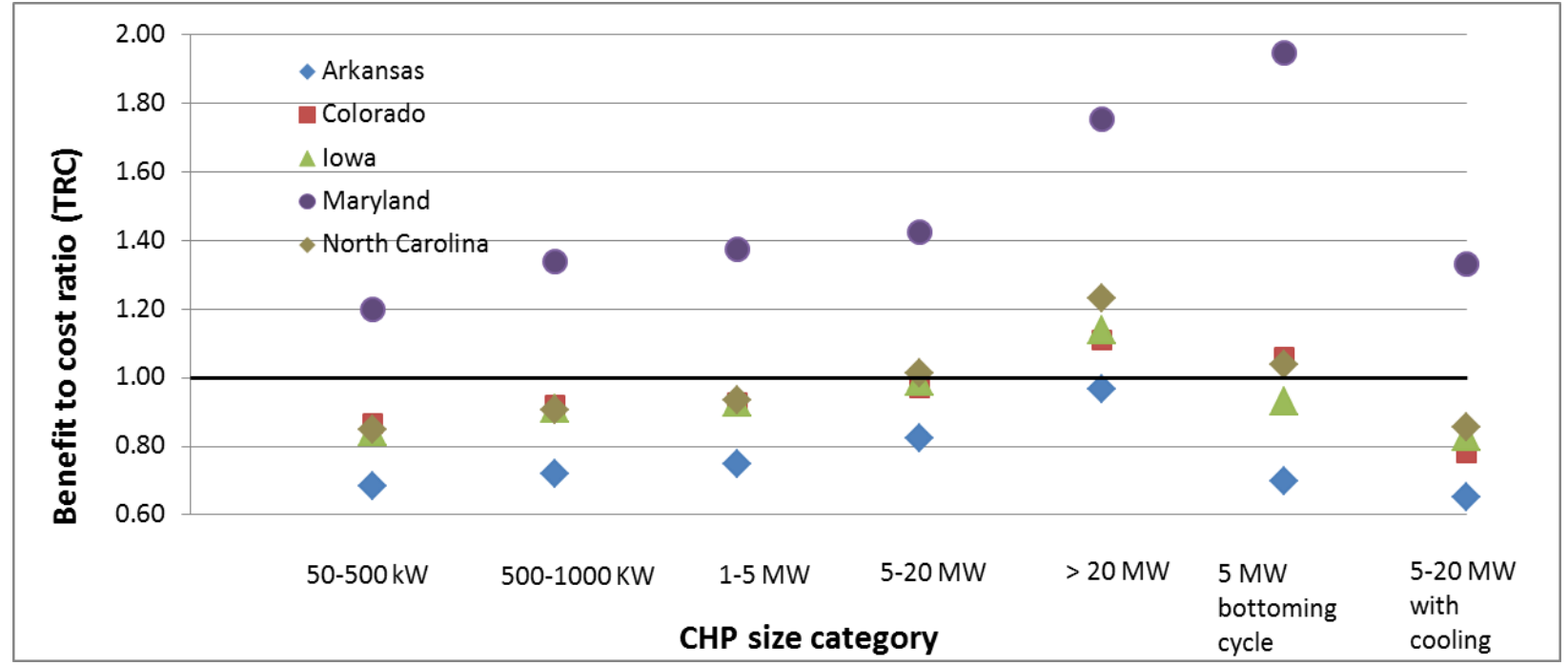

These results show the variation in cost-effectiveness of CHP systems. Larger systems tend to have lower installed costs, higher capacity factors and overall efficiency, which is driven primarily by the CHP generator heat rate, heat recovery system and thermal utilization. A significant driver on cost-effectiveness is the avoided costs (Figure 3). The cost-effectiveness from a TRC perspective correlates well with avoided energy costs; CHP is more cost effective for states with higher avoided costs (e.g., Maryland) vs. states with lower avoided costs (e.g., Arkansas and Iowa). 
Figure 3. Energy avoided costs used for 5 states

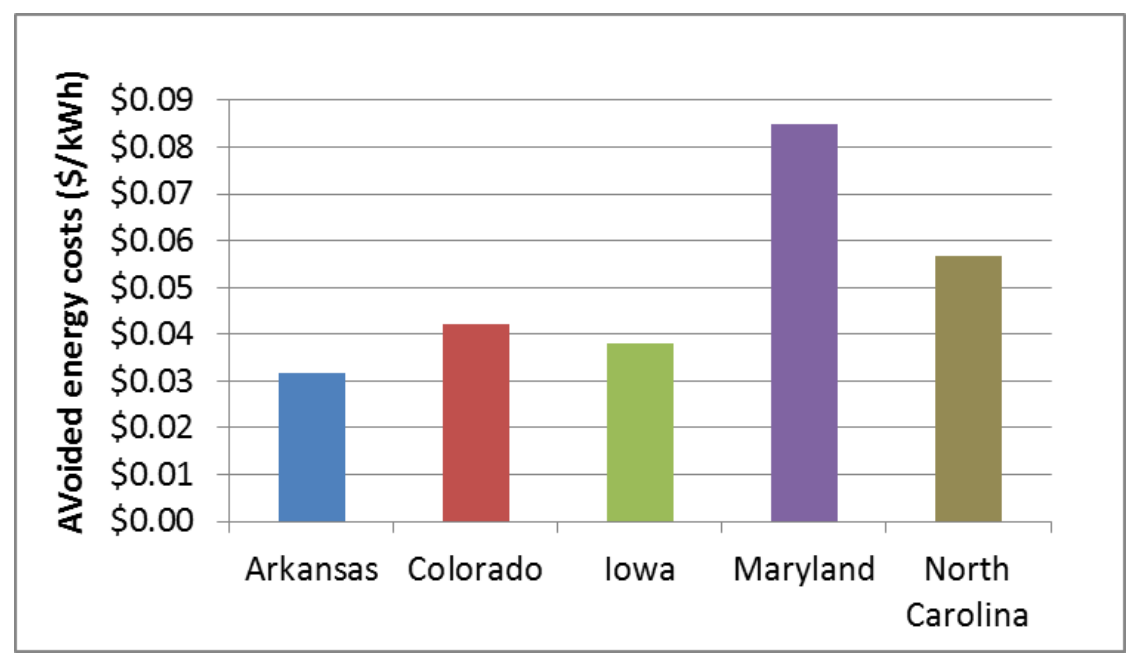

The factors that promote good project economics are well known for CHP systems - high utilization, suitable and steady thermal loads, and larger size. These factors have the same effects on the cost-effectiveness tests. Good project financial performance is a necessary but not sufficient requirement for passing the cost-effectiveness tests. A project that does not have a positive return on standard project economics will not pass the cost-effectiveness tests.

\section{Distribution cost tests and impact of key drivers}

In addition to the base case TRC results, we calculate the other utility cost-effectiveness tests to explore how sensitive the results are to variations in key inputs - capacity factor, thermal utilization, capital cost, avoided costs, inclusion/exclusion of T\&D capacity value, incentive values, inclusion/exclusion of utility standby rates. These parameters were varied independently (i.e., a sensitivity analysis) and simultaneously (i.e., uncertainty analysis) from the base case values $^{19}$. The findings from a $40 \mathrm{MW}$ CHP system in Iowa are used to illustrate the impact on the results across this range of factors.

The inputs for the analysis were collected from a variety of sources. Data on CHP costs and performance are taken from the EPA Catalog of Technologies. ${ }^{20}$ Information on avoided costs was obtained from a variety of sources including utility integrated resource plans, energy efficiency program reports, and supplemented with market data (i.e., natural gas and electricity market futures data). One representative utility was identified for each state and rates from that utility were utilized in the cost tests. ${ }^{21}$

Figure 4 shows the TRC and Figure 5 shows the SCT cost-effectiveness test results for a 40 MW CHP system in Iowa. Following Iowa conventions, the SCT includes a 10 percent adder on the direct avoided costs to account for externalities. The SCT also uses a lower discount rate (3.64 percent) compared to the TRC calculation which uses the utility weighted average cost of 
capital (7.86 percent) which increases the NPV of benefits. The figures show the benefit to cost ratio as a function of utility avoided energy costs.

Figure 4. Total resource cost test, Iowa, 40 MW CHP system

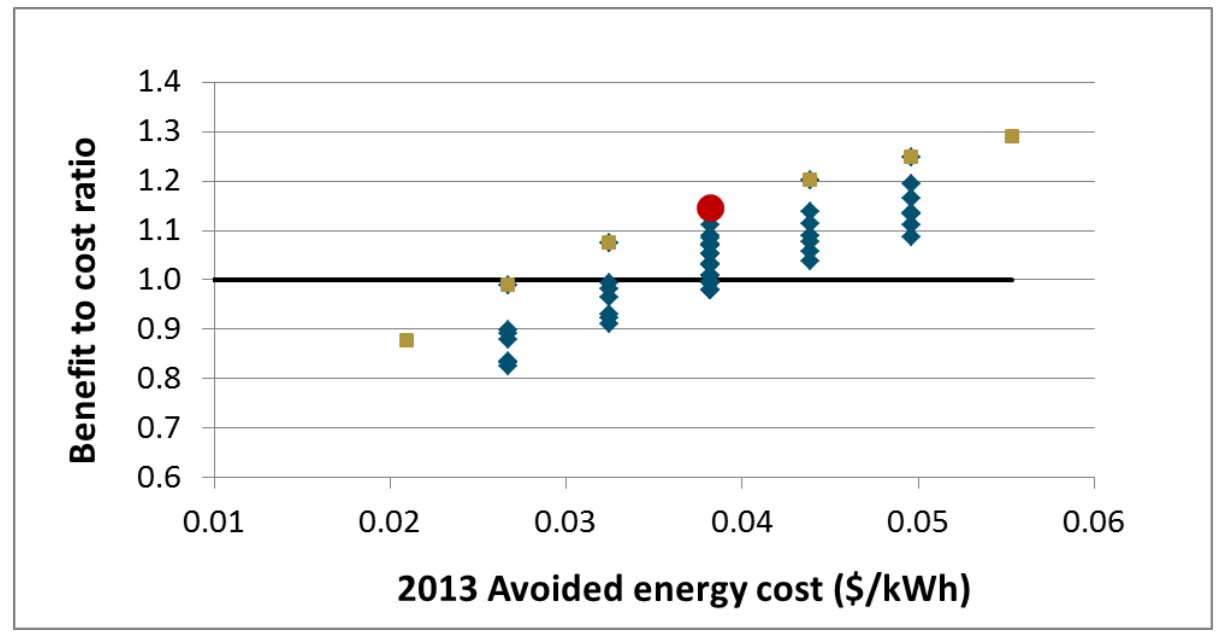

Figure 5. Societal cost test, Iowa, 40 MW CHP system

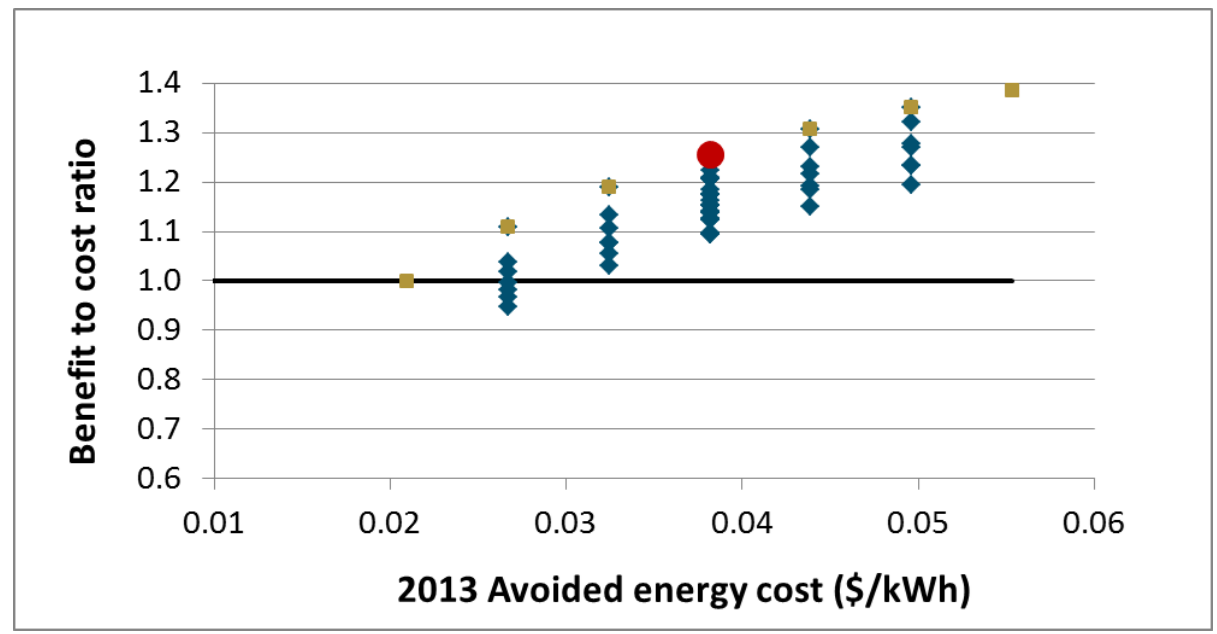

The red marks represent the 'base' case result; the gold markings represent sensitivities in which all inputs are held constant but avoided energy costs are varied; the blue markings reflect scenarios in which multiple inputs were varied, including avoided costs ${ }^{22}$. The results show three interesting trends. First, varying the values of avoided energy costs, arguably, within reasonable ranges, can shift the benefit to cost ratio from not-cost effective (i.e., less than 1) to cost-effective (i.e., greater than 1). Second, for a given avoided cost, the uncertainty is sufficiently large enough to swing the benefit to cost ratio. Third, the shift from TRC to SCT can swing the benefit to cost ratio from below 1 to above 1 for avoided costs ranging from $\sim \$ 0.02 / \mathrm{kWh}$ to $\$ 0.04 / \mathrm{kWh}$.

Standby rates have been a longstanding issue of debate. In the event that CHP programs and systems are designed and operated to provide capacity, the utility may be able to avoid procuring some level of backup capacity resources, which are the motivation for standby charges. We 
investigated the impact of standby charges and demand charges on the participant cost test. The "avoided rate" includes standby charges and demand charges for unscheduled outages, while the "full retail rate" does not assign the participant with standby charges and demand charges for unscheduled outages.

Figure 6 shows the benefit to cost ratio when the participant's bill savings reflects the "full retail rate" vs. the "avoided rate"; the "full retail rate" excludes standby charges and demand charges for unscheduled outages, while the "avoided rate" includes standby charges and demand charges for unscheduled outages. The multiple points on the figure represent all possible combinations of input parameters for the $40 \mathrm{MW}$ system in which hours of operation, thermal utilization, capex, and incentives are varied from their base values within pre-specified ranges. ${ }^{23}$ Removing the standby charges and unscheduled outage demand charges for the $40 \mathrm{MW}$ CHP system improves the benefit-to-cost ratio by approximately 20 percent, as denoted by the 0.2 vertical spacing between the points and the 45 degree diagonal line. This improvement is sufficient to make all cases cost-effective. It is worth noting that the result is specific to the particular utility rate and cannot be interpreted as a generalizable result on standby charges and demand charges that apply to unscheduled outages, but suggests that these charges can, in some cases, be important factors in affecting CHP cost-effectiveness.

Figure 6. Participant cost test with sensitivity on standby rates and demand charges (Iowa, 40 MW CHP system)

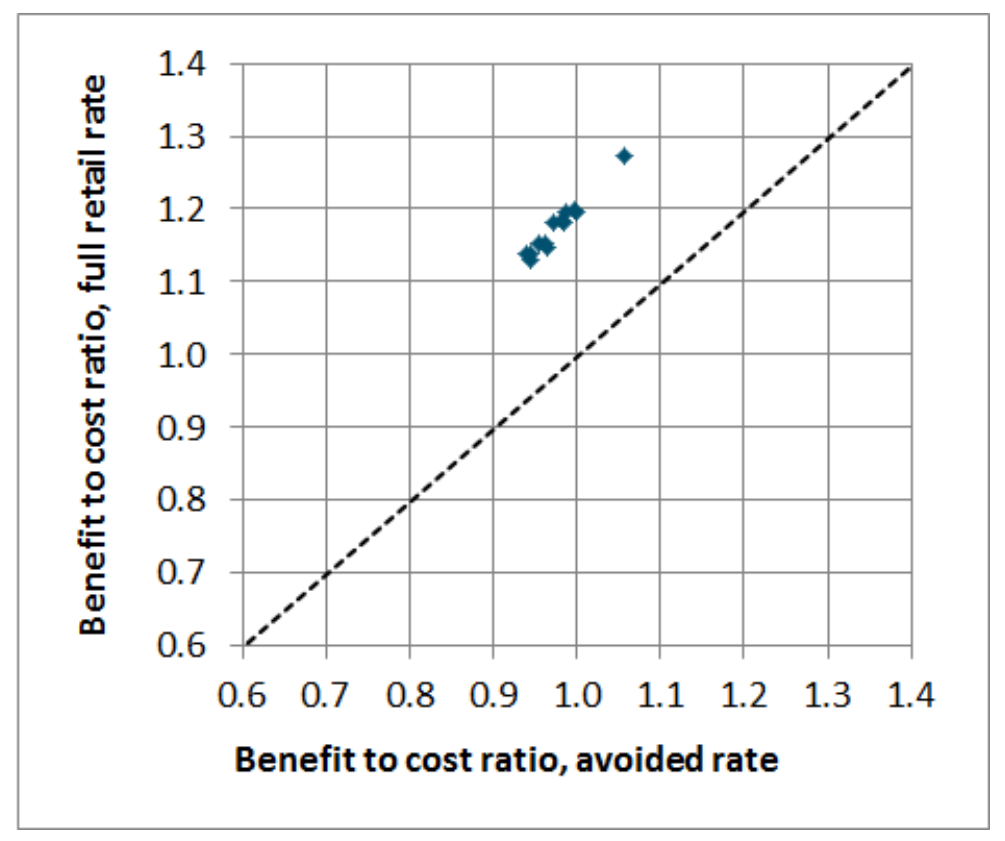

CHP costs and performance characteristics vary by the specific CHP technology type and application. Hence, the cost-effectiveness can vary across CHP application. We analyzed seven different CHP technologies that spanned sizes ranging from $275 \mathrm{~kW}$ to $40 \mathrm{MW}$; six of these were topping cycle CHP and one was a bottoming cycle application. With installed capital costs at $\$ 3,200$ for the smallest CHP system compared to $\$ 1,580$ for a large gas turbine, it is not 
surprising that the cost-effectiveness will vary by technology. Figure 7 shows the SCT benefit to cost ratio across all CHP technologies analyzed as a function of avoided energy costs. For each avoided cost value, multiple cases are shown to illustrate the impact of varying thermal utilization, hours of operation, capital cost and gas avoided costs. Cost-effectiveness generally increases as CHP size increases. As the avoided costs increase, certain CHP systems that were not cost-effective (e.g., 5-20 MW) become cost-effective using the SCT. This type of result is similar to energy efficiency, where certain measures may be more cost-effective than others. Program and/or portfolio level cost-effectiveness is one way to support balanced deployment between less and more cost-effective measures.

Figure 7. Societal cost test benefit to cost ratio vs. avoided costs for all CHP technologies

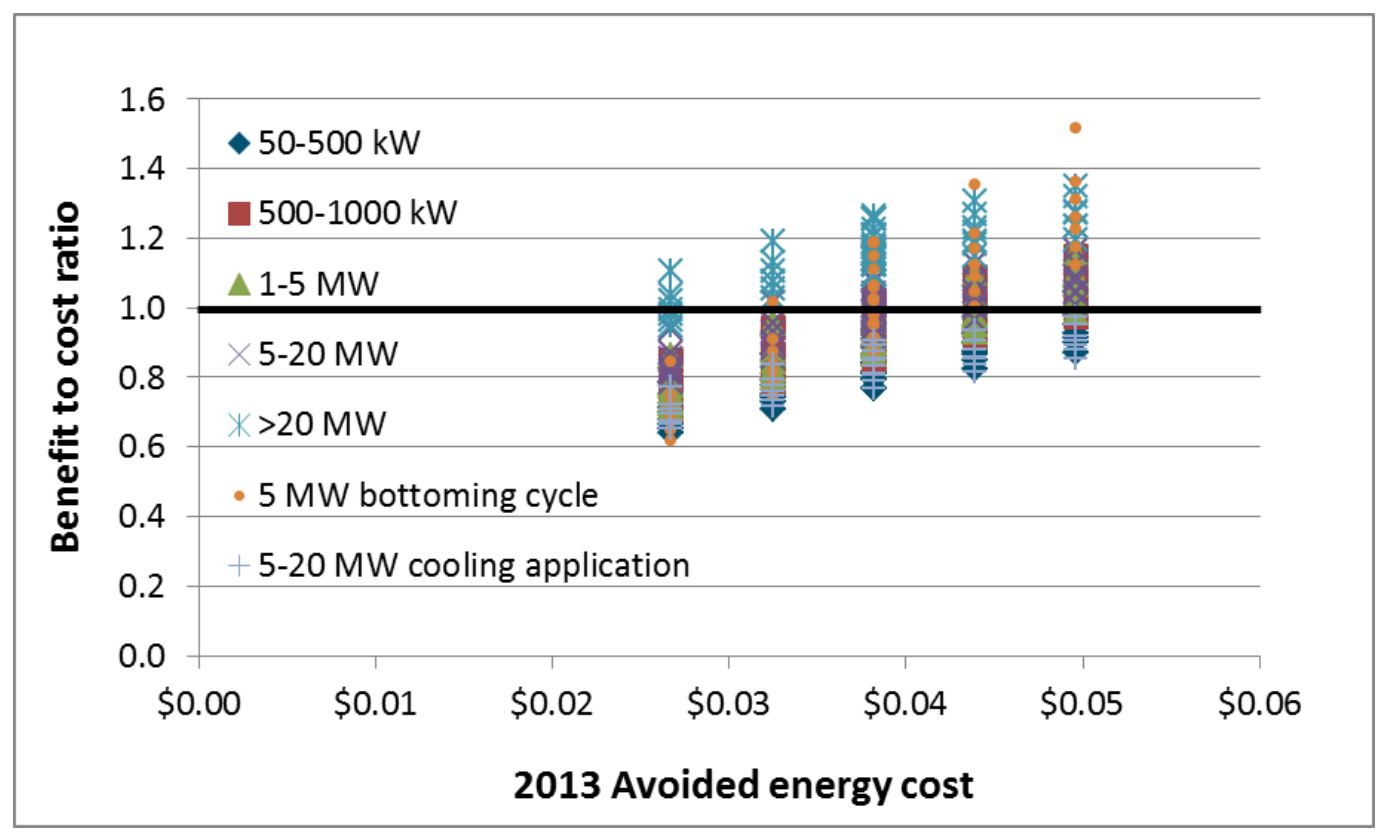

\section{Common findings and insights}

Our analysis highlighted the importance of standardization on inputs, particularly, avoided cost inputs, the value of conducting uncertainty analysis, and that utility-specific analysis is needed to fully understand the impact of certain key (and controversial) issues, such as standby rates and T\&D capacity value.

Avoided energy costs. There is a wide range in avoided costs across the five states and either end of this plausible range can swing the CHP cost-effectiveness result. In states with active integrated resource planning (IRP) or energy efficiency proceedings, the avoided costs were generally higher than avoided costs based on market data or PURPA avoided costs. In many cases, the process was not transparent and key elements of avoided costs were considered confidential to the utility. Generally, a spark spread of $\sim 0.036 \$ / \mathrm{kWh}$ (defined as avoided energy cost minus avoided gas cost multiplied by the net combined cycle heat rate $^{24}$ ) renders CHP cost-effective for all sizes and conditions considered. 
CHP system size. Cost-effectiveness results are size and application specific. While larger CHP systems are typically more cost-effective compared to smaller systems due to economies of scale, we found that even smaller CHP systems were cost-effective in regions with relatively high avoided costs. The societal cost test shows greater benefits for all CHP systems, regardless of size.

T\&D capacity value (avoided capacity value). The inclusion of transmission and distribution capacity value results in roughly $\$ 0.003$ to $\$ 0.01 / \mathrm{kWh}$ of system benefits, assuming T\&D deferral value of $\$ 30 / \mathrm{kW}$-year (based on Xcel Energy in Colorado) to $\$ 80 / \mathrm{kW}$-year (based on Alliant in Iowa). At the lower end of T\&D deferral value, this is unlikely to swing costeffectiveness. At higher T\&D deferral values, this could potentially impact cost-effectiveness.

Standby rates and demand charges. The impact of standby rates and unscheduled demand charges is an important consideration for participant cost-effectiveness. CHP customers can avoid only a portion of their retail rates because of standby service riders and demand charges during system outages. Electric customers who add CHP typically avoid 75-90 percent of the pre- CHP average electric rate. We found that avoiding the full retail rate increases benefit to cost ratios by approximately 3-20 percent. The results were quite varied and utility and application specific.

CHP Performance. CHP performance is an important driver of CHP cost-effectiveness. Proper design and operation of CHP improves cost-effectiveness test results. The base analysis was conducted assuming that all of the thermal energy was effectively utilized. Sensitivity analysis showed that cost-effectiveness declined rapidly as the share of thermal energy utilized declined. Also important, though to a lesser degree, reducing the annual hours of operation of the CHP system makes it harder for its operational benefits to offset the system initial investment costs.

These insights inspire a number of program recommendations that are described in the next section. 


\section{Cost-Effectiveness Test Recommendations for States Establishing CHP Programs}

This paper provides insights on applying cost-effectiveness tests that are normally used to evaluate energy efficiency resources towards CHP systems. In this paper, CHP is treated as a demand side or energy efficiency resource, rather than as a traditional supply side generation resource, which is how CHP is often viewed by regulators. The information in this paper can be used by state utility regulatory commissions that are interested in using cost-effectiveness tests to establish or approve CHP programs. Based on the results from examining five states, this

\section{Identifying CHP Program Goals}

Clearly defined program goals will help ensure the ratepayer-funded CHP program is successful. Program goals can include:

- Deployment of CHP for specific applications / customer types (e.g. manufacturing, hospitals)

- Resiliency and emergency preparedness

- Reduce greenhouse gas emissions

- Support fuel diversity

- Support industrial competitiveness and economic development paper offers four recommendations to inform PUCs in the application of cost-effectiveness tests in developing ratepayer-funded CHP programs:

- Identify goals of the CHP program.

- Establish cost-effectiveness analysis steps, paying particular attention to avoided costs.

- Design performance based incentives that reward electrical and thermal performance.

- Provide visibility into the CHP system performance to promote confidence in utility distribution engineers.

In addition, there are four important steps to ensuring cost-effectiveness tests value CHP in considering the use of ratepayer funds:

- Step 1 - Establish the Framework: The PUC should establish the framework for valuing CHP resources. We propose that the same fundamental DER framework defined in the SPM and used to value other DER technologies, such as energy efficiency, be applied towards valuing CHP. Every state has precedent considering cost-effectiveness of energy efficiency that could be applied and CHP is a significant energy efficiency opportunity.

- Step 2 - Establish Transparent and Appropriate Avoided Costs: the single most important factor in this process is establishing transparent and appropriate DER avoided costs. Commissions may choose to initiate a proceeding in this regard or adopt existing avoided costs established and used for conventional energy efficiency. The stakeholder process of a proceeding can be used to resolve the more controversial issues, such as the inclusion or exclusion of T\&D capacity value. 
- Step 3 - Consider all Five Cost-Effectiveness Tests: Each cost-effectiveness test provides a different perspective and all five cost-effectiveness tests should be considered. The TRC and SCT provide a measure of overall cost-effectiveness and are the appropriate tests to determine overall cost-effectiveness to a region as a whole; the TRC is the primary cost test used by most states (70\%) to assess cost-effectiveness of energy efficiency programs. ${ }^{25}$ When applied to CHP, the TRC and SCT tests should be carefully calculated to account for all changes in energy consumption - both increases and decreases. For example, increased natural gas use at the site by the CHP system, reduced boiler fuel to meet site thermal needs, reduced site electricity consumption, and reduced transmission and distribution losses on the grid. The PCT can be used to tune incentives that better encourage customer adoption of CHP without making incentives overly generous. The RIM and PACT tests can be used to evaluate rate impacts and utility costs, respectively.

- Step 4 - Use the Cost-Effectiveness Tests to Inform Program Incentive Levels and Encourage High Performing CHP: Finally, design programs to support high efficiency and high performing systems. The primary economic driver is efficiency; therefore, consider screening applications for incentives based on expected performance and using performance-based incentive mechanisms. Like any DER program, there is a balance between complexity and ease of use which must be considered. Recognize that customers with CHP have the incentive to use CHP systems well to maximize bill savings and the return on their investment. 


\section{Endnotes}

\footnotetext{
${ }^{1}$ Ratepayer-funded energy efficiency programs are also known as "customer-funded" or "consumer-funded" energy efficiency programs. Energy consumers do pay for energy efficiency products and services with their own funds. This paper uses the term ratepayer-funded energy efficiency programs to capture the products and services organized through the pooling of utility ratepayer funds and offered through a formal program administrator. For additional information on this topic, see the Regulatory Assistance Project's paper "Who Should Deliver RatepayerFunded Energy Efficiency?” authored by Rich Sedano, http://raponline.org/document/download/id/4707.

${ }^{2}$ Other states with CHP programs include Arizona, Illinois, Massachusetts, and New Jersey. Information obtained from State Incentives for Renewables \& Efficiency (DSIRE), accessed August 2014, http://www.dsireusa.org/ .

${ }^{3}$ Calculations based on 5 MW CHP system, $80 \%$ capacity factor (7,000 hrs/yr), 35\% of input energy converted to electricity, $40 \%$ of input energy converted to useful thermal energy, $35.6 \%$ grid power plant conversion efficiency, $7.5 \%$ T\&D losses.

${ }^{4}$ U.S. Department of Energy and U.S. Environmental Protection Agency, 2012. "Combined Heat and Power: A Clean Energy Solution," Figure 1, page 7, http://www1.eere.energy.gov/manufacturing/distributedenergy/pdfs/chp_clean_energy_solution.pdf.

${ }^{5}$ U.S. Environmental Protection Agency Combined Heat and Power Partnership. Accessed July 2014, www.epa.gov/chp/basic/environmental.html.
}

${ }^{6}$ Executive Order 13624, Accelerating Investment in Industrial Energy Efficiency, August 30, 2012. Available at http://www.gpo.gov/fdsys/pkg/DCPD-201200674/pdf/DCPD-201200674.pdf.

${ }^{7}$ U.S. Department of Energy and U.S. Environmental Protection Agency, Combined Heat and Power: A Clean Energy Solution, August 2012. Available at https://www1.eere.energy.gov/manufacturing/distributedenergy/pdfs/chp_clean_energy solution.pdf .

${ }^{8}$ National Action Plan for Energy Efficiency (2008). Understanding Cost-Effectiveness of Energy Efficiency Programs: Best Practices, Technical Methods, and Emerging Issues for Policy-Makers. Energy and Environmental Economics, Inc. and Regulatory Assistance Project, http://www.epa.gov/cleanenergy/documents/suca/costeffectiveness.pdf. The National Action Plan for Energy Efficiency represents findings among a group of public and private sector stakeholders that includes utilities, local, state and federal agencies, and other key stakeholders.

${ }^{9}$ Standard Practice for the Cost-Benefit Analysis of Conservation and Load Management Programs, California Energy Commission, 1983.

${ }^{10}$ National Action Plan for Energy Efficiency (2008). Understanding Cost-Effectiveness of Energy Efficiency Programs: Best Practices, Technical Methods, and Emerging Issues for Policy-Makers. Energy and Environmental, Table 2-2, Page 2-2, http://www.epa.gov/cleanenergy/documents/suca/cost-effectiveness.pdf .

${ }^{11}$ The California standard practice manual was first developed in February 1983. It was later revised and updated in 1987-88 and 2001; a Correction Memo was issued in 2007. The 2001 California SPM can be found at http://www.cpuc.ca.gov/NR/rdonlyres/004ABF9D-027C-4BE1-9AE1CE56ADF8DADC/0/CPUC_STANDARD_PRACTICE_MANUAL.pdf and 2007 Correction Memo can be found at http://www.cpuc.ca.gov/NR/rdonlyres/A7C97EB0-48FA-4F05-9F3D4934512FEDEA/0/2007SPMClarificationMemo.doc .

${ }^{12}$ National Action Plan for Energy Efficiency (2008). Understanding Cost-Effectiveness of Energy Efficiency Programs: Best Practices, Technical Methods, and Emerging Issues for Policy-Makers. Energy and Environmental Economics, Inc. and Regulatory Assistance Project, http://www.epa.gov/cleanenergy/documents/suca/costeffectiveness.pdf.

${ }^{13}$ An additional reference that provides more detail on each of these components is Chapter 3 of the National Action Plan for Energy Efficiency "Guide to Resource Planning with Energy Efficiency," http://www.epa.gov/cleanenergy/documents/suca/resource_planning.pdf. 
${ }^{14}$ Amendments to PURPA in 2005 and related FERC decisions have limited the applicability of PURPA in certain regions, particularly for facilities larger than $20 \mathrm{MW}$. For more information, see Chapter 4 of the SEE Action "The Guide to Successful Implementation of State Combined Heat and Power Policies, "

https://www4.eere.energy.gov/seeaction/publication/guide-successful-implementation-state-combined-heat-andpower-policies.

${ }^{15}$ See the National Plan for Energy Efficiency (Reference 12), and the American Council for an Energy-Efficient Economy (2012), A national survey of state policies and practices for the evaluation of ratepayer-funded energy efficiency programs, Report U122, http://www.aceee.org/research-report/u122.

${ }^{16}$ California Public Utility Commission, Attachment A of D.09.08-026, http://docs.cpuc.ca.gov/word_pdf/FINAL_DECISION/105928.pdf

${ }^{17}$ California Self Generation Incentive Program, http://www.cpuc.ca.gov/PUC/energy/DistGen/sgip/ .

New York Combined heat and power performance program, http://www.nyserda.ny.gov/Energy-Efficiency-andRenewable-Programs/Commercial-and-Industrial/CI-Programs/Combined-Heat-and-Power.aspx .

Connecticut Clean Energy Finance and Investment Authority Programs supporting CHP deployment, http://www.ct.gov/deep/cwp/view.asp?a=4405\&q=499472\&deepNav_GID=2121.

Maryland Save Energy Now, http://energy.maryland.gov/SEN/CHP.html

${ }^{18}$ See the National Plan for Energy Efficiency, Reference 12, and the American Council for an Energy-Efficient Economy (2012). A national survey of state policies and practices for the evaluation of ratepayer-funded energy efficiency programs. Report U122, http://www.aceee.org/research-report/u122.

19 The inputs were varied as follows: hours of operation and thermal utilization were varied in combinations of $(0,-$ $20 \%),(-20 \%, 0 \%)$, and $(-10 \%,-10 \%)$ of base case values (8059 hours, $100 \%)$; gas and electric avoided costs were varied from $-30 \%$ to $+30 \%$ in $15 \%$ increments of base case values; installed capital cost was varied by $10 \%$ and $20 \%$ of base case cost $(\$ 1,520 / \mathrm{kW})$.

${ }^{20}$ U.S. Environmental Protection Agency. Catalog of CHP Technologies, http://www.epa.gov/chp/technologies.html.

${ }^{21}$ This paper used the following as representative utilities for the states evaluated: Entergy (Arkansas), Xcel Energy (Colorado), Alliant (Iowa), Baltimore Gas and Electric (Maryland), and Duke (North Carolina).

22 The blue points reflect scenarios in which all the inputs were varied as follows: hours of operation and thermal utilization were varied in combinations of $(0,-20 \%),(-20 \%, 0 \%)$, and $(-10 \%,-10 \%)$ of base case values $(8059$ hours, $100 \%$ ); gas and electric avoided costs were varied from $-30 \%$ to $+30 \%$ in $15 \%$ increments of base case values; installed capital cost was varied by $10 \%$ and $20 \%$ of base case cost $(\$ 1,520 / \mathrm{kW})$.

${ }^{23}$ The inputs were varied as follows: hours of operation and thermal utilization were varied in combinations of $(0,-$ $20 \%),(-20 \%, 0 \%)$, and $(-10 \%,-10 \%)$ of base case values (8059 hours, $100 \%)$; installed capital cost was varied by $10 \%$ and $20 \%$ of base case cost $(\$ 1520 / \mathrm{kW})$; incentives were varied by $0 \%, 25 \%$ and $50 \%$ of the base incentive level of $20 \%$ of the base case cost (capped at $\$ 40$ million).

${ }^{24}$ The spark spread calculation is based on a net combined cycle heat rate of 7,500 Btu/kWh.

${ }^{25}$ American Council for an Energy-Efficient Economy (2012), A national survey of state policies and practices for the evaluation of ratepayer-funded energy efficiency programs, Report U122, http://www.aceee.org/researchreport/u122. 